\title{
From efficacy to effectiveness and beyond: what next for brief interventions in primary care?
}

\author{
Amy O'Donnell ${ }^{1}$ *, Paul Wallace ${ }^{2}$ and Eileen Kaner ${ }^{1}$ \\ ${ }^{1}$ Institute of Health and Society, Newcastle University, Newcastle upon Tyne, UK \\ ${ }^{2}$ Department of Primary Care and Population Health, University College London, London, UK
}

\section{Edited by:}

Hugo López-Pelayo, Fundació Clínic per la Recerca Biomèdica, Spain

Reviewed by:

Roberta Agabio, University of Cagliari, Italy

Marcin Wojnar, Medical University of Warsaw, Poland

${ }^{*}$ Correspondence:

Amy O'Donnell, Institute of Health and Society, Newcastle University, Baddiley-Clark Building, Richardson Road, Newcastle upon Tyne NE2 4AX, UK

e-mail: amy.odonnell@

newcastle.ac.uk
Background: Robust evidence supports the effectiveness of screening and brief alcohol interventions in primary healthcare. However, lack of understanding about their "active ingredients" and concerns over the extent to which current approaches remain faithful to their original theoretical roots has led some to demand a cautious approach to future roll-out pending further research. Against this background, this paper provides a timely overview of the development of the brief alcohol intervention evidence base to assess the extent to which it has achieved the four key levels of intervention research: efficacy, effectiveness, implementation, and demonstration.

Methods: Narrative overview based on (1) the results of a review of systematic reviews and meta-analyses of the effectiveness of brief alcohol intervention in primary healthcare and (2) synthesis of the findings of key additional primary studies on the improvement and evaluation of brief alcohol intervention implementation in routine primary healthcare.

Results: The brief intervention field seems to constitute an almost perfect example of the evaluation of a complex intervention. Early evaluations of screening and brief intervention approaches included more tightly controlled efficacy trials and have been followed by more pragmatic trials of effectiveness in routine clinical practice. Most recently, attention has shifted to dissemination, implementation, and wider-scale roll-out. However, delivery in routine primary health remains inconsistent, with an identified knowledge gap around how to successfully embed brief alcohol intervention approaches in mainstream care, and as yet unanswered questions concerning what specific intervention component prompt the positive changes in alcohol consumption.

Conclusion: Both the efficacy and effectiveness of brief alcohol interventions have been comprehensively demonstrated, and intervention effects seem replicable and stable over time, and across different study contexts. Thus, while unanswered questions remain, given the positive evidence amassed to date, research efforts should maintain a continued focus on promoting sustained implementation of screening and brief alcohol intervention approaches in primary care to ensure that those who might benefit from screening and brief alcohol interventions actually receive such support.

Keywords: brief alcohol intervention, efficacy, effectiveness, implementation, research needs, secondary prevention, primary care

\section{INTRODUCTION}

Brief interventions for alcohol provide a clinically effective and cost-effective means of identifying and addressing alcohol-related problems when delivered in primary healthcare settings (1-4). Originating in the field of smoking cessation (5), and grounded in social cognitive theory (6), brief alcohol interventions aim to detect problems at an early stage, when they are most amenable to adjustment, to promote positive behavior change (7), and thus avoid the development of more serious future problems in an individual (8).

\section{WHAT IS THE BASIS FOR BRIEF INTERVENTIONS FOR ALCOHOL?}

Brief intervention comprises two broad modalities. First, simple structured advice in the form of personalized feedback on how to address problematic drinking behavior as well as information and/or advice on how to avoid its adverse consequences. This form of intervention is typically delivered in one to five sessions, which are short in duration [a review by Kaner et al. who found a mean of $25 \mathrm{~min}$ per intervention (9)]. Second, extended or more intensive intervention, using counselling and other psycho-therapeutic techniques such as motivational interviewing or cognitive behavioural therapy (CBT), which may extend up to 50 minutes per session $(9,10)$. These more intensive interventions may be delivered either in a single appointment, or via a series of related sessions and the overall treatment exposure has been reported to be $60-175$ minutes overall (9). Nevertheless, while the content and delivery style of brief interventions may vary, all are 
designed to promote awareness of the negative effects of drinking and to motivate positive behavior change (11). The core elements of brief alcohol intervention are based on "FRAMES" (Feedback, Responsibility, Advice, Menu, Empathy, and Self-efficacy) principles (12), and important components include drawing out individuals' beliefs and attitudes about drinking, their self-efficacy or sense of personal confidence about changing their drinking, and a view about how their drinking sits in relation to other people's drinking behavior (normative comparison) (13).

\section{WHAT ARE THE OVERALL FINDINGS FROM THE EVIDENCE?}

From the first study of the effects of opportunistic brief intervention carried out in Malmo, Sweden in the early 1980s (14) over three decades of research has been undertaken both locally and internationally to develop these simple technologies to assist with the identification of individuals at risk from their alcohol consumption, and the delivery of short, cost-effective interventions in community and health-care settings. A recent review of systematic reviews, covering a total of 56 unique primary healthcare-based randomized controlled trials, found consistent evidence for the effectiveness of brief alcohol interventions in reducing hazardous and harmful drinking when delivered in primary care settings (15). However, some of the more recent individual large scale pragmatic trials have failed to demonstrate significant differences between the effect sizes in the control and intervention groups $(16,17)$. In addition, as Heather has emphasized, while the evidence base for the implementation of brief structured advice as a form of opportunistic ASBI appears reasonably sound, this is not the case for extended, intensive interventions based more explicitly on motivational interviewing principles (18), despite the sound theory informing such approaches (19).

\section{WHY MIGHT SOME STUDIES FAIL TO FIND SIGNIFICANT TREATMENT EFFECTS?}

A consistent trend in trials of brief intervention is that of reduction of alcohol consumption in both the control and active intervention conditions (20-22). It is not yet clear if this is due to an artifact of participating in the research process itself (see below) or a response to active ingredients of behavior change, which may be provided to participants allocated to the control condition (23). These include feedback, provision of bibliometric information, and cursory advice about alcohol, which may be embedded with other lifestyle behaviors such as smoking or physical activity. Despite awareness of these issues, there has been little progress to address concerns about assessment reactivity, for example, through the use of Solomon 4-group designs (24-26).

\section{WHAT DO WE KNOW ABOUT THE KEY ELEMENTS OF INTERVENTION AND HOW WELL THEY ARE DELIVERED?}

Whilst there is undoubtedly a considerable and largely convincing body of literature supporting the overall effectiveness of brief interventions for alcohol, as the recent McCambridge review confirmed, our understanding of their "active ingredients" remains limited (27). Evidence suggests that for interventions to achieve statistically significant improvements in alcohol outcomes, they should include at least two of the following three elements - feedback, advice, and goal-setting (28). However, the results of a study by Bertholet and colleagues were far less clear-cut, finding that across different populations and settings, intervention characteristics viewed as central to efficacious brief motivational interviews were inconsistent predictors of drinking outcome (29). Further, as both Whitlock and Beich have emphasized (28, 30), given the inevitable "helping relationship" that exists between patient and practitioner, it remains challenging to isolate the impact that the additional support general practitioners might have on intervention effectiveness, particularly when such interventions may be delivered on multiple occasions, and via multiple modalities. There has been some recent work that focused on specific behavior change techniques embedded in advice or counseling (31) but we are not closer to understanding potential therapist effects (either skill, rapport-building, or trust) or the interaction between intervention per se and other aspects of recipients' lives (policy, corporate behavior, and family or personal context). There are also concerns as to whether current brief intervention approaches remain faithful to their theoretical roots. It has therefore been suggested that poor delivery of brief interventions coupled with potential content drift, should result in a cautious approach to future roll-out, whilst additional research is carried out to establish the efficacy of individual intervention components more conclusively (29).

Taking all the above considerations into account, it seems timely to review the current state of the screening and brief alcohol intervention evidence base to determine the extent to which further research is actually required, and to consider which research questions such studies might most usefully examine. After all, any additional research must build upon previous work to save public time and money. For "while replication is an important part of the scientific method, a field needs to progress rather than merely generate volume" (32). Importantly, the development, evaluation, initial adoption, and wider roll-out of a new health intervention or treatment should ideally be supported by a sequence of research studies, ranging from basic "proof of concept" research to demonstration studies. Flay identifies four key levels of experimental research: efficacy (or explanatory) trials; treatment effectiveness (or pragmatic) studies; implementation studies; and finally, program evaluation (or demonstration) research to measure the actual impact of an intervention at wider population level once an intervention becomes part of large scale, mainstream care $(33,34)$. These levels are both interlinked and interdependent, thus most research is best conceptualized as existing on a continuum, from optimized to naturalistic conditions, as opposed to being easily positioned within one distinct study category (35). Crucially, however, efficacy must be demonstrated before effectiveness is assessed, and the latter is a necessary pre-condition for wider dissemination and subsequent adoption (36).

Against this background, this paper aims to provide an overview of the development of the screening and brief alcohol intervention research field in primary health care drawing primarily on published systematic reviews in the field, supplemented with key recent literature to ensure the evidence presented reflects the cutting edge of this field. In doing so, it will assess the extent to which the existing ASBI evidence base has achieved Flay's four key levels of intervention research (efficacy $\rightarrow$ effectiveness $\rightarrow$ implementation $\rightarrow$ demonstration) (33, 
34), which in turn, will help highlight any outstanding questions for future research.

\section{METHODS}

First, the paper draws on the results of a recent overview of systematic reviews and meta-analyses of the effectiveness of brief alcohol intervention in this setting (15). This overview searched key electronic databases (MEDLINE, EMBASE, PsycInfo, The Cochrane Database, The Database of Abstracts of Reviews of Reviews, and the Alcohol and Alcohol Problems Science Database) for systematic reviews and meta-analyses of studies examining the effectiveness of brief alcohol intervention in comparison to control conditions in primary healthcare settings, which were published between 2002 and 2012. Second, the paper synthesizes the findings of more recently published primary studies focused on the improvement and evaluation of the implementation of brief interventions for alcohol in routine primary healthcare to ensure the presented evidence reflects the state-of-the-art in this field.

For the purposes of this paper, primary healthcare has been operationalized to include all immediately accessible general healthcare facilities but not emergency settings. Brief intervention comprises a single session and/or up to a maximum of five sessions of engagement with a patient, and the provision of information and advice designed to achieve a reduction in risky alcohol consumption or alcohol-related problems. Heavy drinking is defined as drinking in excess of $60 \mathrm{~g}$ of alcohol per day for men and $40 \mathrm{~g}$ for women (37). Hazardous drinking is consumption at a level, or in such a pattern, that increases an individual's risk of physical or psychological consequences (38), while harmful drinking is defined by the presence of these consequences (39). Alcohol consumption, at a dependent level, results in repetitive problems, affecting three or more areas of life, including a strong desire or compulsion to use alcohol, inability to control use, and withdrawal from and tolerance to alcohol (40).

\section{RESULTS}

\section{EFFICACY, EFFECTIVENESS, IMPLEMENTATION, AND PROGRAME EVALUATION: THE FOUR PHASES OF BRIEF ALCOHOL INTERVENTION RESEARCH}

\section{Level 1: Do brief interventions work? Efficacy studies on brief alcohol interventions}

An efficacy trial is designed to evaluate what an intervention achieves under optimum conditions (33). It provides a test of (a) a well-specified and standardized treatment or therapy that (b) is made available in a uniform fashion, within standardized contexts or settings, to a specific target audience, which (c) completely accepts, participates in, complies with, or adheres to the treatment/programe as delivered (33). According to the US Society for Prevention Research $(36,41)$, efficacy testing necessitates the conduct of a minimum of two robust trials [defined as those which include tightly defined populations; psychometrically reliable measures and data collection procedures; rigorous statistical analysis; consistent positive effects (without adverse impacts); and one or more long-term follow-ups]. The randomized controlled trial is generally considered to be the "gold-standard" for intervention evaluation in medical research and the most rigorous way of determining whether a cause-effect relation exists between treatment and outcome (42). This is because this methodological approach is specifically designed to minimize bias and potentially confounding variables through randomization of study participants to prevent systematic differences between intervention groups in any factors (both known and unknown); and double blinding to ensure that the preconceived views of subjects and/or clinicians cannot systematically bias the assessment of outcomes (43).

Clinical drug trials, where a discrete dose of a pharmacological agent is delivered to patients, face fewer challenges in meeting the required standards of treatment efficacy. For behavioral interventions, which generally involve significant inter-personal interaction in the delivery and receipt of advice or counseling, the conditions are more challenging. There is inherent complexity where human actors are required to be a substantial part of "the therapy" (44). Although it can be argued that practitioners often deliver and/or explain the pharmaco-therapy in drug trials, the tablet or pill is generally regarded as the key active ingredient not the explanation or advice per se. Despite this challenge, an attempt has been made to disaggregate the component parts of brief alcohol intervention in trial-based evaluations (by characteristics of practitioners, patients, delivery settings, intervention content, scope for flexibility, skill-based training, implementation support, and fidelity monitoring) to assess the extent to which trial-based evaluations show features of uniformity and standardization (efficacy) or not (9). The conclusion of this work was that evaluations in this field sit on a continuum from efficacy to effectiveness trials, because a perfect model of either extreme is hard to achieve. In general, the older trials, which tended to include more tightly controlled evaluations with high levels of internal validity, demonstrated consistently positive outcome effects. Moreover, a series of sensitivity analyses excluding trials with less than adequate features of methodology found persistently positive outcomes. Thus, proof of concept via efficacy trials seems to have been comprehensively demonstrated (45) and more recently re-confirmed by a further systematic review by Jonas et al. (46).

\section{Level 2: Do brief interventions work in the real world of primary care? Effectiveness trials}

Efficacy trials can establish whether an intervention works (or does more good than harm) when delivered in optimum conditions; effectiveness trials determine whether those benefits continue to be realized in more real-world settings. Sufficient replicability and stability of effects are important aspects of this work especially in "typical" conditions of delivery where availability, compliance or acceptance, and measurement factor may vary (33). As Flay writes "an intervention will be effective only if an efficacious treatment/program is delivered/implemented in such a way as to be made available to an appropriate target audients in a manner acceptable to them (i.e. that they will be receptive to, participate in, comply with, or adhere to)" (33).

A recent review of reviews identified at least 56 separate randomized controlled trials of screening and brief alcohol interventions in primary health care, which consistently reported that brief alcohol interventions are effective at reducing hazardous and harmful drinking in primary healthcare, with weekly alcohol consumption the most commonly reported outcome (15). A 
key issue here, is the size of the outcome effect and the extent to which it is diminished (or not) in more variable pragmatic evaluations. In 2007, meta-analysis of the results from 25 RCTs of screening and brief intervention by Kaner et al. (9) reported an average reduction in the quantity of alcohol drunk of $38 \mathrm{~g} /$ week for brief intervention compared with control conditions [95\% CI (confidence interval): 23-54 g]. More recently, analysis of the pooled results from 23 RCTs and 6 systematic reviews by Jonas et al. (46) found a slightly increased reduction of $49 \mathrm{~g} /$ week for adults aged 18-64 (95\% CI: 33-66 g). Thus outcome effects appear to have been generally stable over time as trials have become increasingly pragmatic in nature (9). Finally, in addition to reduced alcohol consumption, this field of work has regularly reported reductions in other outcomes such as alcohol-related problems (9) and reduced health-care utilization (47) and mortality (48). Importantly, delivery by a range of practitioners in primary healthcare settings has beneficial effects (49), although findings of one review suggest that the effect sizes are greater if delivered by doctors (50). In summary, there appears to be ample evidence of replicability and consistency of effects on a number of parameters.

This said, while the overall evidence base seems to show that brief alcohol interventions are both efficacious and effective when delivered in primary care settings, some individual large scale pragmatic trials have reported null findings. For example, a recent large UK trial (SIPS) reported no significant differences in hazardous and harmful drinking status in patients receiving simple feedback after screening plus a patient information leaflet (the control condition), those receiving $5 \mathrm{~min}$ of structured advice, and those receiving a further $20 \mathrm{~min}$ brief lifestyle counseling (16). This finding accords with three systematic reviews that focused on control conditions only and found consistently reduced drinking in these groups over time (20-22). It may be that the mere fact of participation in a brief intervention trial may be associated with positive behavior change. This may be due to a general "Hawthorn effect," whereby increased attention or scrutiny might influence drinking (51). It may be that most individuals who agree to participate in a trial have already started a change process. Moreover, given the fact that extreme measures of behavior tend to shift to less extreme positions over time (known as regression to the mean), such reductions in control groups may also be explained by natural reductions in heavy drinking over time (52). Finally, there is growing evidence to suggest that patients' reactions to the screening or measurement activity itself could influence their decision to cut down their alcohol consumption (known as assessment reactivity) $(53,54)$. Conversely, while it is possible that individuals with lower reported levels of consumption might increase their drinking over time, this is rarely captured in alcohol trials where only risky drinkers are included at enrolment. Nevertheless, an interesting trend in this field is that the definition of heavier or risky drinkers seems to have been falling over time (9). For example in a 2007 review, average weekly consumption at enrollment (baseline) was 55 standard drink units in the earliest trial (55) but was only 25 standard drink units in the most recent trial (16). Hence, it is possible that the scope for regression to the mean might be reducing in this field. Furthermore, the cumulative (pooled) metaanalyses reported in successive systematic reviews reveal positive outcome effects "over and above" those seen or expected in control conditions (15).

\section{Level 3: What factors promote widespread adoption of brief interventions into routine practice? Implementation trials}

Whilst there have been successive attempts to encourage the routine delivery of brief alcohol interventions in day-to-day practice, most efforts have demonstrated limited success (56-60), and implementation of this form of preventive care remains inconsistent. In the UK, for example, although survey data suggest that GPs see both preventative medicine and alcohol intervention as increasingly high priority public health areas, and they generally view primary health care as an appropriate setting to raise and discuss alcohol issues (61), most do not routinely ask patients about their drinking (62). In recognition of this mismatch, there has been an increased focus on implementation research to test potential approaches to improve their delivery (63).

Implementation studies may take a number of forms, exploring the many influences on patient, healthcare professional, and organizational behavior in either healthcare or population settings (63). In the alcohol intervention field, there has arguably been most progress in identifying the various obstacles experienced by practitioners seeking to deliver screening and brief alcohol interventions in routine primary health care. Some of the barriers to the provision of brief alcohol interventions identified to date concern the socio-cultural, interactional and attitudinal factors that influence their delivery by individual primary healthcare practitioners (64, 65). For example, there is an evidence to suggest that many GPs remain unconvinced that patients will heed advice to change their drinking behavior, particularly those patients drinking at heavier or dependent levels (66-68). Practitioners are also concerned that they might offend patients by discussing alcohol, or at least view alcohol as a "delicate" subject to raise in the standard consultation situation $(65,68)$, which potentially risks jeopardizing the patient-doctor relationship $(69,70)$. This "role insecurity" (71) may also relate to the potential impact that practitioners' own drinking practices may have on intervention delivery, alongside confusion about what advice they should actually be delivering on lower risk drinking (61).

In addition, previous research also points toward a series of structural and organizational factors that influence alcohol intervention delivery. Lack of training or suitable intervention materials $(68,72)$, inadequate financial incentives $(73,74)$, unsupportive specialist alcohol service provision $(3,67)$, and everyday time pressures $(67,75)$ has all been identified by GPs and other health practitioners as barriers to their successful engagement in and delivery of brief interventions for alcohol (32, 59, 62, 64, 73, 76-79). Moreover, these barriers are often interrelated. Thus GPs' discussions around alcohol are shaped by both the practical challenge of incorporating discussions about alcohol within the pressured, time-limited consultation process and their own (and the patient's) complex social, cultural, and moral beliefs about what constitutes "normal" versus "problematic"drinking $(64,80,81)$.

Alongside research to identify notable barriers to the routine delivery of screening and brief alcohol intervention in primary care, there have also been studies exploring facilitating factors. For example, Screening, Brief Intervention, and Referral to Treatment 
(SBIRT) is US-based program to promote the use of evidencebased practice to identify, reduce, and prevent problematic use, abuse, and dependence on alcohol and illicit drugs (82-86). One key message arising from this program of activities has been that effective training strategies for health professionals are an essential first step in the successful implementation of SBIRT, with teambased learning a potentially promising strategy to help maintain newly learned clinical skills (87). In addition, Ronzani et al. have shown the importance of involving managers in the dissemination of screening strategies and brief interventions to increase their implementation rates (88). Results from comparative work carried out in New Zealand, England, and Catalonia demonstrated the need to tailor procedures to fit with local circumstances, to break the process down into clinically acceptable steps, and to negotiate implementation strategies and timing taking into account local needs and competing demands to successfully embed intervention activity (89). The recent developments in the use of digitally mediated brief interventions (eBI) delivered via the internet and mobile phones represent another way of dealing with these issues (90). These offer practitioners a way to avoid the need to engage their patients directly in a discussion about alcohol, while at the same time providing an opportunity to reflect on their drinking behavior in a secure and confidential setting (see Internet applications for screening and brief interventions for alcohol in primary care settings - implementation and sustainability by Wallace and Bendtsen in this issue for more on this subject).

Regarding work that actively promotes uptake and adoption of brief interventions in practice, the largest study conducted to date was part of a World Health Organisation Collaborative project. This study found that active dissemination strategies were needed to ensure that practitioners were aware of the evidence on brief interventions, whilet both training and support were needed to convert this knowledge into action (60). Moreover, a systematic review and meta-analysis of strategies to engage practitioners in brief intervention activity found that a specific focus on alcohol per se and multi-component support programes were more effective (79) than focusing on several behavior and just a single education or support strategy. Bringing this field right up to date is the optimizing delivery of health care interventions (ODHIN) study, an ongoing Europe wide project involving research institutions from nine European countries. This trial has a factorial design and it aims to assess the impact on practitioner behavior of out-reach training, financial incentives, and the opportunity to refer patients to an electronic brief intervention programe, both individually and in differing combinations of approaches. This study is due to report in 2015 .

\section{Level 4: Wider roll-out work: Demonstration studies}

A key limitation of earlier implementation research, however, is that changes in practitioner behavior tend to be limited to the time-frame of each individual study that attempts to promote screening and brief alcohol intervention. When the research work ends, the focus on screening and brief alcohol intervention also tends to stop. A significant challenge is to find ways of embedding this activity in mainstream clinical work to achieve sustained delivery (70), and also to be able to measure when and how often it occurs, and to whom it is delivered.
The development of national alcohol strategies, specific guidance for practitioners on when and how to deliver screening and brief interventions, and national payment programs for ASBI has recently been introduced in the UK to promote their wider roll-out $(91,92)$. Khadjesari et al. drew on routine UK general practice data (covering 382,609 patients, drawn from over 500 general practices) to examine the impact of financial incentives on the rates of screening for alcohol-use disorders (93). It found that following the introduction of screening incentives, relatively high rates of newly registered adult patients ( $76 \%$ nationally) were being screened for an alcohol-use disorder in English general practice settings. In addition, research conducted in the North East of England, which used routine data to compare recorded rates of delivery between general practices that were incentivized or non-incentivized for ASBI activity, determined that overall, practices associated with higher recorded rates of key ASBI service indicators were signed up to pay-for-performance schemes (94). Finally, and moving the field beyond the UK, the ongoing EU co-funded research brief interventions in the treatment of alcohol-use disorders in relevant settings (BISTAIRS) project seeks to intensify the implementation of brief alcohol intervention across Europe, including through the identification and dissemination of existing pockets of evidencebased good practice in established national primary health-care programs, with results from this work expected in 2015 (95).

\section{CONCLUSION}

This paper demonstrates that overall, there is a plentiful outcome evaluation literature, which consistently reports positive effects of screening and brief alcohol intervention when delivered in primary care. Much of this literature is of a moderate to high quality, and the outcome effects persist even when the less well designed studies are discounted from the assessment. As such, we have surely long passed the point of needing to ask the question "do these interventions work?", or even "do they work in the real world of primary care?." Both efficacy and effectiveness have been comprehensively demonstrated through this substantial body of evidence, and intervention effects seem replicable and indeed stable over time, and across different study contexts. Indeed, with the benefit of hindsight, the brief intervention field seems to constitute an almost perfect example of the evaluation of a complex intervention (96). Early evaluations of screening and brief intervention approaches included more tightly controlled efficacy trials and were followed by more pragmatic trials of effectiveness in routine clinical practice. Attention then shifted to dissemination, implementation (60), and wider-scale roll-out (97). Nevertheless, we still seem to be a long way from consistent delivery of brief interventions to the majority of heavy drinking patients in routine primary care, and day-to-day implementation of this approach seems to be at best very modest (94). Moreover, while new studies appear at regular intervals in the published literature, these are still primarily focused on the assessment of intervention effects rather than on how to embed brief intervention approaches in mainstream care.

No field of research work is perfect however, and especially one that has been evolving over a 30 year period. Consequently, it is not surprising that a considerable degree of heterogeneity exists within the screening and brief intervention literature or that there can often seem to be a re-treading over previously covered ground. 
There is also a genuinely interesting and as yet unanswered question concerning what specific factors prompt the positive changes in alcohol consumption that occur after brief alcohol intervention that undoubtedly needs further examination. However, the search for these "active ingredients" should not delay progress in rolling out these interventions into health systems for patient benefit. Many people do not fully understand how their car actually works, yet most still successfully drive them each day. Given the positive evidence amassed to date, research efforts should maintain a continued focus on promoting sustained implementation of screening and brief alcohol intervention approaches in primary care.

Moreover, frontline practitioners responsible for the implementation of any policy or health program may make adaptations based on the availability of resources, compatibility with organizational or professional values, expertise, and knowledge (98), resulting in their "reinvention" of the intervention (99). The research community needs to accept this reality which might result in some loss of scientific purity (98). For the credibility of research in practice is judged less by its rigor than how it fits with professional wisdom and experience, and understanding of what "best evidence" actually means in day-to-day health care (100). Looking further forward, therefore, the key challenge for the brief intervention field in the future is to embrace translational research (101), in which academics, practitioners, and policymakers work in closer partnership, potentially also with patients, in order to understand their world-view more clearly, and identify mutually acceptable ways of embedding brief interventions in practice (102).

\section{ACKNOWLEDGMENTS}

This work was in part supported by the health program of the European Union as part of the BISTAIRS research project (agreement number 2011_1204). The sole responsibility lies with the author and the Executive Agency is not responsible for any use that may be made of the information contained therein. For further information, visit the project website at www.bistairs.eu.

\section{REFERENCES}

1. Hutubessy R, Chisholm D, Edejer T-T; WHO-CHOICE. Generalised CostEffectiveness Analysis for National-Level Priority Setting in the Health Sector. Cost Effectiveness and Resource Allocation. Geneva: World Health Organisation (2003).

2. Raistrick D, Heather N, Godfrey C. Review of the Effectiveness of Treatment for Alcohol Problems. London: NHS, National Treatment Agency for Substance Misuse (2006).

3. Bernstein E, Topp D, Shaw E, Girard C, Pressman K, Woolcock E, et al. A preliminary report of knowledge translation: lessons from taking screening and brief intervention techniques from the research setting into regional systems of care. Acad Emerg Med (2009) 16(11):1225-33. doi:10.1111/j.1553-2712.2009. 00516.x

4. Lock C. Screening and brief alcohol interventions: what, why, who, where and when? A review of the literature. J Subst Abuse (2004) 9(2):91-101. doi:10.1080/14659890410001665096

5. Russell M, Wilson C, Taylor C, Baker C. Effect of general practitioners' advice against smoking. Br Med J (1979) 283:231-4. doi:10.1136/bmj.2.6184.231

6. Kaner EF, Newbury-Birch D, Heather N. Brief intervention. In: Miller PM, editor. Evidence-Based Addiction Treatment. Burlington, MA: Academic Press (2009). p. 189-213.

7. Winett RA. A framework for health promotion and disease prevention programs. Am Psychol (1995) 50(5):341-50. doi:10.1037/0003-066X.50.5.341
8. Babor T, Higgins-Biddle J. Brief Intervenation for Hazardous and Harmful Drinking: A Manual for Use in Primary Care. Geneva: World Health Organization, Department of Mental Health and Substance Dependence (2001).

9. Kaner E, Beyer F, Dickinson H, Pienaar E, Campbell F, Schlesinger C, et al. Effectiveness of brief alcohol interventions in primary care populations. Cochrane Database Syst Rev (2007) (2):CD004148. doi:10.1002/14651858.CD004148. pub3

10. National Institute for Health and Clinical Excellence. Alcohol-Use Disorders Preventing the Development of Hazardous and Harmful Drinking (2010). Available from: http://guidanceniceorguk/H24

11. HoC Health Committee. Alcohol: first report of session 2009-10. House of Commons. London: The Stationery Office Limited (2010).

12. Miller W, Sanchez V. Motivating Young Adults for Treatment and Lifestyle Change. Notre Dame, IN: University of Notre Dame Press (1993). p. 55-580.

13. Kaner A, O’Donnell A. Chapter 40: brief intervention: does it work? In: Boyle P, Boffetta P, Zatonski W, Lowenfels AB, Brawley O, Burns H, et al., editors. Alcohol, Science, Policy and Public Health. Oxford: Oxford University Press (2013). p. 325-31.

14. Kristenson H, Ohlin H, Hulten-Nosslin M-B, Trell E, Hood B. Identification and intervention of heavy drinking in middle-aged men: results and follow up of 24-60 months of long-term study with randomised controls. Alcohol Clin Exp Res (1983) 7:203-10.

15. O'Donnell A, Anderson P, Newbury-Birch D, Schulte B, Schmidt C, Reimer J, et al. The impact of brief alcohol interventions in primary healthcare: a systematic review of reviews. Alcohol Alcohol (2014) 49(1):66-78. doi:10.1093/alcalc/ agt170

16. Kaner E, Bland M, Cassidy P, Coulton S, Dale V, Deluca P, et al. Effectiveness of screening and brief alcohol intervention in primary care (SIPS trial): pragmatic cluster randomised controlled trial. Br Med J (2013) 346:e8501. doi:10.1136/bmj.e8501

17. Christopher CB, Sharon AS, Kerenza H, David C, Tim P, Clio S, et al. Training practitioners to deliver opportunistic multiple behaviour change counselling in primary care: a cluster randomised trial. BMJ (2013) 346:f1191. doi:10.1136/bmj.f1191

18. Heather N. Breaking new ground in the study and practice of alcohol brief interventions. Drug Alcohol Rev (2010) 29(6):584-8. doi:10.1111/j.1465-3362. 2010.00204.x

19. Heather N. Toward an understanding of the effective mechanisms of alcohol brief interventions. Alcohol Clin Exp Res (2014) 38(3):626-8. doi:10.1111/acer. 12336

20. Bernstein J, Bernstein E, Heeren T. Mechanisms of change in control group drinking in clinical trials of brief alcohol intervention: implications for bias towards the null. Drug Alcohol Rev (2010) 29:498-507. doi:10.1111/j.14653362.2010.00174.x

21. Jenkins RJ, McAlaney J, McCambridge J. Change over time in alcohol consumption in control groups in brief intervention studies: systematic review and meta-regression study. Drug Alcohol Depend (2009) 100(1-2):107-14. doi:10.1016/j.drugalcdep.2008.09.016

22. McCambridge J, Kypri K. Can simply answering research questions change behaviour? Systematic review and meta analyses of brief alcohol intervention trials. PLoS One (2011) 6(10):e23748. doi:10.1371/journal.pone.0023748

23. Michie S, Prestwich A, de Bruin M. Importance of the nature of comparison conditions for testing theory-based interventions. Health Psychol (2010) 29:468-70. doi:10.1037/a0020844

24. Bien TH, Miller WR, Tonigan JS. Brief interventions for alcohol problems: a review. Addiction (1993) 88(3):315-36. doi:10.1111/j.1360-0443.1993. tb00820.x

25. Solomon RL. An extension of control group design. Psychol Bull (1949) 46(2):137-50.

26. McCambridge J, Butor-Bhavsar K, Witton J, Elbourne D. Can research assessments themselves cause bias in behaviour change trials? A systematic review of evidence from Solomon 4-group studies. PLoS One (2011) 6(10):e25223. doi:10.1371/journal.pone.0025223

27. McCambridge J, Cunningham JA. The early history of ideas on brief interventions for alcohol. Addiction (2014) 109(4):538-46. doi:10.1111/add.12458

28. Whitlock EP, Polen MR, Green CA, Orleans T, Klein J. Behavioral counseling interventions in primary care to reduce risky/harmful alcohol use by adults: a summary of the evidence for the U.S. Preventive Services Task Force. Ann Intern Med (2004) 140(7):557-68. doi:10.7326/0003-4819-140-7-200404060-00017 
29. Bertholet N, Palfai T, Gaume J, Daeppen J-B, Saitz R. Do brief alcohol motivational interventions work like we think they do? Alcohol Clin Exp Res (2014) 38(3):853-9. doi:10.1111/acer.12274

30. Beich A, Thorsen T, Rollnick S. Screening in brief intervention trials targeting excessive drinkers in general practice: systematic review and meta-analysis. BMJ (2003) 327(7414):536-42. doi:10.1136/bmj.327.7414.536

31. Michie S, Whittington C, Hamoudi Z, Zarnani F, Tober G, West R. Identification of behaviour change techniques to reduce excessive alcohol consumption. Addiction (2012) 107(8):1431-40. doi:10.1111/j.1360-0443.2012.03845.x

32. Kaner E. Brief alcohol intervention: time for translational research. Addiction (2010) 105:960-1. doi:10.1111/j.1360-0443.2009.02848.x

33. Flay BR. Efficacy and effectiveness trials (and other phases of research) in the development of health promotion programs. Prev Med (1986) 15(5):451-74. doi:10.1016/0091-7435(86)90024-1

34. Thorpe K, Zwarenstein M, Oxman A, Treweek S, Furberg C, Altman D, et al. A pragmatic-explanatory continuum indicator summary (PRECIS): a tool to help trial designers. J Clin Epidemiol (2009) 62:464-75. doi:10.1016/j.jclinepi. 2008.12.011

35. Gartlehner G, Hansen R, Nissman D, Lohr K, Carey T. A simple and valid tool distinguished efficacy from effectiveness studies. J Clin Epidemiol (2006) 59:1040-8. doi:10.1016/j.jclinepi.2006.01.011

36. Flay B, Biglan A, Boruch R, Gonzalez Castro F, Gottfredson D, Kellam S, et al. Standards of evidence: criteria for efficacy, effectiveness and dissemination. Prev Sci (2005) 6(3):151-75. doi:10.1007/s11121-005-5553-y

37. Rehm J, Roerecke M. Reduction of drinking in problem drinkers and all-cause mortality. Alcohol Alcohol (2013) 48(4):509-13. doi:10.1093/alcalc/ agt021

38. Edwards G, Arif A, Hodgson R. Nomenclature and classification of drug and alcohol related problems: a WHO memorandum. Bull World Health Organ (1981) 59:225-42.

39. World Health Organisation. International Classification of Diseases. 10th ed. Geneva: World Health Organisation (1992).

40. World Health Organisation. International Statistical Classification of Diseases and Related Health Problems. 10th ed. Geneva: World Health Organisation (2007).

41. Flay B, Biglan A, Boruch R, Castro F, Gottfredson D, Kellam S, et al. Standards of Evidence: Criteria for Efficacy, Effectiveness and Dissemination. Falls Church, VA: Society for Prevention Research (2004).

42. Sibbald B, Roland M. Understanding controlled trials: why are randomised controlled trials important? BMJ (1998) 316(7126):201. doi:10.1136/bmj.316 7146.1719

43. Higgins J, Green S, editors. Cochrane Handbook for Systematic Reviews of Interventions Version 5.1.0. The Cochrane Collaboration (2011). Available from: www.cochrane-handbook.org

44. Flay B, Cook T. Evaluation of mass media prevention campaigns. In: Rice R, Paisley W, editors. Public Communication Campaigns. Beverley Hills, CA: Sage (1981). p. 239-64.

45. Kaner E. NICE work if you can get it: development of national guidance incorporating screening and brief intervention to prevent hazardous and harmful drinking in England. Drug Alcohol Rev (2010) 29(6):589-95. doi:10.1111/j.1465-3362.2010.00236.x

46. Jonas D, Garbutt J, Brown J, Amick H, Brownley K, Council C, et al. Screening, Behavioral Counseling, and Referral in Primary Care To Reduce Alcohol Misuse. Rockville, MD: Agency for Healthcare Research and Quality (2012).

47. Bray JW, Zarkin GA, Davis KL, Mitra D, Higgins-Biddle JC, Babor TF. The effect of screening and brief intervention for risky drinking on health care utilization in managed care organizations. Med Care (2007) 45(2):177-82. doi:10.1097/01.mlr.0000252542.16255.fc

48. Cuijpers P, Riper H, Lemmers L. The effects on mortality of brief interventions for problem drinking: a meta-analysis. Addiction (2004) 99(7):839-45. doi:10.1111/j.1360-0443.2004.00778.x

49. Huibers M, Beurskens A, Bleijenberg G, van Schayck C. The Effectiveness of Psychosocial Interventions Delivered by General Practitioners. Review. London: Cochrane Database of Systematic Reviews (2003).

50. Sullivan L, Tetrault J, Braithwaite S, Turner B, Fiellin DA. A meta-analysis of the efficacy of nonphysician brief interventions for unhealthy alcohol use: implications for the patient-centered medical home. Am J Addict (2011) 20:343-56. doi:10.1111/j.1521-0391.2011.00143.x
51. Franke RH, Kaul JD. The Hawthorne experiments: first statistical interpretation. Am Sociol Rev (1978) 43:623-43.

52. McCambridge J, Kypri K, McElduff P. Regression to the mean and alcohol consumption: a cohort study exploring implications for the interpretation of change in control groups in brief intervention trials. Drug Alcohol Depend (2014) 135(1):156-9. doi:10.1016/j.drugalcdep.2013.11.017

53. McCambridge J, Day M. Randomized controlled trial of the effects of completing the alcohol use disorders identification test questionnaire on self-reported hazardous drinking. Addiction (2008) 103(2):241-8. doi:10.1111/j.1360-0443. 2007.02080.x

54. Walters ST, Vader AM, Harris TR, Jouriles EN. Reactivity to alcohol assessment measures: an experimental test. Addiction (2009) 104(8):1305-10. doi:10.1111/ j.1360-0443.2009.02632.x

55. Wallace P, Cutler S, Haines A. Randomized controlled trial of general practitioner intervention with excessive alcohol consumption. BMJ (1988) 297:663-8. doi:10.1136/bmj.297.6649.663

56. van Beurden I, Anderson P, Akkermans R, Grol R, Wensing M, Laurant M. Involvement of general practitioners in managing alcohol problems: a randomized controlled trial of a tailored improvement programme. Addiction (2012) 107(9):1601-11. doi:10.1111/j.1360-0443.2012.03868.x

57. Sepppanen K, Aalto M, Seppa K. Institutionalization of brief alcohol intervention in primary health care - the Finnish case. Alcohol Clin Exp Res (2012) 36(8):1456-61. doi:10.1111/j.1530-0277.2012.01755.x

58. Anderson P, Kaner E, Wutzke S, Funk M, Heather N, Wensing M, et al. Attitudes and managing alcohol problems in general practice: an interaction analysis based on findings from a WHO Collaborative Study. Alcohol Alcohol (2004) 39(4):351-6. doi:10.1093/alcalc/agh072

59. Nilsen P, Aalto M, Bendtsen P, Seppa K. Effectiveness of strategies to implement brief alcohol intervention in primary healthcare: a systematic review. Scand J Prim Health Care (2006) 24:5-15. doi:10.1080/02813430500475282

60. Funk M, Wutzke S, Kaner E, Anderson P, Pas L, McCormick R, et al. A multicountry controlled trial of strategies to promote dissemination and implementation of brief alcohol intervention in primary health care: findings of a world health organization collaborative study. J Stud Alcohol (2005) 66(3): 379-88.

61. Hutchings D, Cassidy P, Dallolio E, Pearson P, Heather N, Kaner E. Implementing screening and brief alcohol interventions in primary care: views from both sides of the consultation. Prim Health Care Res Dev (2006) 7(3):221-9. doi:10.1191/1463423606pc289oa

62. Lock C, Wilson G, Kaner E, Cassidy P, Christie M, Heather N. A Survey of General Practitioners' Knowledge, Attitudes and Practices Regarding the Prevention and Management of Alcohol-Related Problems: An Update of a World Health Organisation Survey Ten Years On. London: Alcohol Education and Research Council (2009).

63. Peters DH, Taghreed A, Olakunle A, Irene Akua A, Nhan T. Implementation research: what it is and how to do it. BMJ (2013) 347:f6753. doi:10.1136/bmj. f6753

64. Rapley T, May C, Kaner E. Still a difficult business? Negotiating alcohol-related problems in general practice consultations. Soc Sci Med (2006) 63:2418-28. doi:10.1016/j.socscimed.2006.05.025

65. Moriarty H, Stubbe M, Chen L, Tester R, Macdonald L, Dowell A, et al. Challenges to alcohol and other drug discussions in the general practice consultation. Fam Pract (2012) 29:213-22. doi:10.1093/fampra/cmr082

66. Thom B, Tellez C. A difficult business: detecting and managing alcohol problems in general practice. Br J Addict (1986) 81:405-18. doi:10.1111/j.13600443.1986.tb00347.x

67. Kaner E, Heather N, McAvoy B, Lock C, Gilvarry E. Intervention for excessive alcohol consumption in primary heath care: attitudes and practices of English general practitioners. Alcohol Alcohol (1999) 34(4):559-66. doi:10.1093/alcalc/ 34.4.559

68. Aira M, Kauhanen J, Larivaara P, Rautio P. Factors influencing inquiry about patients' alcohol consumption by primary health care physicians: qualitative semi-structured interview study. Fam Pract (2003) 20(3):270-5. doi:10.1093/ fampra/cmg307

69. Tam M, Zwar N, Markham R. Australian general practitioner perceptions of the detection and screening of at-risk drinking, and the role of the AUDIT-C: a qualitative study. BMC Fam Pract (2013) 14:121. doi:10.1186/ 1471-2296-14-121 
70. May C, Rapley T, Kaner E. Clinical reasoning, clinical trials and risky drinkers in everyday primary care: a qualitative study of British general practitioners. Addict Res Theory (2006) 14(4):387-97. doi:10.1080/16066350600609883

71. Shaw S, Cartwright A, Spratley T, Harwin J. Responding to Drinking Problems. Baltimore, MD: University Park Press (1978).

72. Aalto M, Pekuri P, Seppa K. Primary health care nurses' and physicians' attitudes, knowledge and beliefs regarding brief intervention for heavy drinkers. Addiction (2001) 96:305-11. doi:10.1046/j.1360-0443.2001.96230514.x

73. Johnson M, Jackson R, Guillaume L, Meier P, Goyder E. Barriers and facilitators to implementing screening and brief intervention for alcohol misuse: a systematic review of qualitative evidence. J Public Health (2010) 33(3):412-21. doi:10.1093/pubmed/fdq095

74. Kersnick J, Poplas Susic T, Kolsek M, Svab I. What may stimulate general practitioners to undertake screening and brief intervention for excess alcohol consumption in Slovenia? A focus group study. J Int Med Res (2009) 37:1561-9. doi:10.1177/147323000903700534

75. Beich A, Gannik D, Malterud K. Screening and brief intervention for excessive alcohol use: qualitative interview study of the experiences of general practitioners. Br Med J (2002) 325:870. doi:10.1136/bmj.325.7369.870

76. Lock C, Kaner E, Lamont S, Bond S. A qualitative study of nurses' attitudes and practices regarding brief alcohol intervention in primary health care. $J A d v$ Nurs (2002) 39(4):333-42. doi:10.1046/j.1365-2648.2002.02294.x

77. HoC Public Accounts Committee. Reducing Alcohol Harm: Health Services in England for Alcohol Misuse. London: The Stationery Office Ltd., House of Commons (2009).

78. Gual A, Sabadini MD. Implementing alcohol disorders treatment throughout the community. Curr Opin Psychiatry (2011) 24:203-7. doi:10.1097/YCO. 0b013e3283459256

79. Anderson P, Laurant M, Kaner E, Wensing M, Grol R. Engaging general practitioners in the management of hazardous and harmful alcohol consumption: results of a meta-analysis. J Stud Alcohol (2004) 65:191-9.

80. Amaral M, Ronzani T, Souza-Formigoni ML. Process evaluation of the implementation of a screening and brief intervention program for alcohol risk in primary health care: an experience in Brazil. Drug Alcohol Rev (2010) 29:162-8. doi:10.1111/j.1465-3362.2009.00120.x

81. Nygaard P, Aasland O. Barriers to implementing screening and brief interventions in general practice: findings from a qualitative study in Norway. Alcohol Alcohol (2011) 46(1):52-60. doi:10.1093/alcalc/agq073

82. Nilsen P, McCambridge J, Karlsson N, Bendtsen P. Brief interventions in routine health care: a population-based study of conversations about alcohol in Sweden. Addiction (2011) 106(10):1748-56. doi:10.1111/j.1360-0443.2011. 03476.x

83. Makela P, Havio M, Seppa K. Alcohol-related discussions in health care-a population view. Addiction (2011) 106(7):1239-48. doi:10.1111/j.1360-0443.2010. 03356.x

84. Babor TF, McRee BG, Kassebaum PA, Grimaldi PL, Ahmed K, Bray J. Screening, brief intervention, and referral to treatment (SBIRT). Subst Abuse (2007) 28(3):7-30. doi:10.1300/J465v28n03_03

85. Madras BK, Compton WA, Avula D, Stegbauer T, Stein JB, Clark HW. Screening, brief interventions, referral to treatment (SBIRT) for illicit drug and alcohol use at multiple healthcare sites: comparison at intake and 6 months later. Drug Alcohol Depend (2009) 99(1-3):280-95. doi:10.1016/j.drugalcdep.2008.08.003

86. McCance-Katz EF, Satterfield J. SBIRT: a key to integrate prevention and treatment of substance abuse in primary care. Am J Addict (2012) 21(2):176-7. doi:10.1111/j.1521-0391.2011.00213.x

87. Shellenberger S, Seale JP, Harris DL, Johnson JA, Dodrill CL, Velasquez MM. Applying team-based learning in primary care residency programs to increase patient alcohol screenings and brief interventions. Acad Med (2009) 84(3):340-6. doi:10.1097/ACM.0b013e3181972855

88. Ronzani TM, Mota DCB; Souza ICW. Prevenção do uso de álcool na atenção primária em municípios do estado de Minas Gerais. Rev Saude Publica (2009) 43:51-61. doi:10.1590/S0034-89102009000800009
89. McCormick R, Docherty B, Segura L, Colom J, Gual A, Cassidy P, et al. The research translation problem: alcohol screening and brief intervention in primary care - real world evidence supports theory. Drugs (Abingdon Engl) (2010) 17(6):732-48. doi:10.3109/09687630903286800

90. Struzzo P, Scafato E, McGregor R, Della Vedova R, Verbano L, Lygidakis C, et al. A randomised controlled non-inferiority trial of primary care-based facilitated access to an alcohol reduction website (EFAR-FVG): the study protocol. BMJ Open (2013) 3(2):e002304. doi:10.1136/bmjopen-2012-002304

91. NICE. Alcohol-Use Disorders: Preventing the Development of Hazardous and Harmful Drinking: NICE Public Health Guidance 24. London: National Institute for Health and Clinical Excellence (2010).

92. Employers NHS. Clinical Directed Enhanced Service (DES) Guidance for GMS Contract 2008/9. London: NHS Employers and British Medical Association (BMA) (2008).

93. Khadjesari Z, Marston L, Petersen I, Nazareth I, Walters K. Alcohol consumption screening of newly-registered patients in primary care: a cross-sectional analysis. Br J Gen Pract (2013) 63(615):706-12. doi:10.3399/bjgp13X673720

94. O’Donnell A, Haighton K, Chappel D, Shevills C, Kaner E. Can routine data help evaluate the implementation of brief alcohol intervention in primary health care? Alcohol Clin Exp Res (2013) 37:11A-253A. doi:10.1111/ acer. 12162

95. Schulte B. BISTAIRS (Brief interventions in the treatment of alcohol use disorder in relevant settings) Project Site 2012 [cited 2014 13th May] (2014). Available from: http://www.bistairs.eu/

96. Campbell M, Fitzpatrick R, Haines A, Kinmonth AL, Sandercock P, Spiegelhalter D, et al. Framework for design and evaluation of complex interventions to improve health. Br Med J (2000) 321(7262):694-6. doi:10.1136/bmj.321.7262. 694

97. Heather N. A long-standing World Health Organization collaborative project on early identification and brief alcohol intervention in primary health care comes to an end. Addiction (2007) 102(5):679-81. doi:10.1111/j.1360-0443. 2007.01844.x

98. Nutley S, Walter I, Davies HTO. Using Evidence: How Research Can Inform Public Services. Bristol: University of Bristol (2007).

99. Klesges LM, Dzewaltowski DA, Glasgow RE. Review of external validity reporting in childhood obesity prevention research. Am J Prev Med (2008) 34(3):216-23. doi:10.1016/j.amepre.2007.11.019

100. Wharf Higgins J. Navigating through translational research: a social marketing compass. Health Mark Q (2011) 28(1):1-15. doi:10.1080/07359683.2010. 495302

101. Straus SE, Graham ID, Mazmanian PE. Knowledge translation: resolving the confusion. J Contin Educ Health Prof (2006) 26(1):3-4. doi:10.1002/chp.45

102. Woolf SH. The meaning of translational research and why it matters. JAMA (2008) 299(2):211-3. doi:10.1001/jama.2007.26

Conflict of Interest Statement: The authors declare that the research was conducted in the absence of any commercial or financial relationships that could be construed as a potential conflict of interest.

Received: 18 May 2014; accepted: 12 August 2014; published online: 28 August 2014. Citation: O'Donnell A, Wallace P and Kaner E (2014) From efficacy to effectiveness and beyond: what next for brief interventions in primary care? Front. Psychiatry 5:113. doi: $10.3389 /$ fpsyt.2014.00113

This article was submitted to Addictive Disorders and Behavioral Dyscontrol, a section of the journal Frontiers in Psychiatry.

Copyright (C) 2014 O'Donnell, Wallace and Kaner. This is an open-access article distributed under the terms of the Creative Commons Attribution License (CC BY). The use, distribution or reproduction in other forums is permitted, provided the original author(s) orlicensor are credited and that the original publication in this journal is cited, in accordance with accepted academic practice. No use, distribution or reproduction is permitted which does not comply with these terms. 